\title{
Pricing for Products in Website-Dominant Static Group-buying
}

\author{
Sheng $\mathrm{Li}^{1,2}$, Huifang Feng ${ }^{1} \&$ Yu Huang ${ }^{3}$ \\ ${ }^{1}$ School of Business Administration, Southwestern University of Finance \& Economics, Chengdu, China \\ ${ }^{2}$ School of Management, Chengdu University of Traditional Chinese Medicine, Chengdu, China \\ ${ }^{3}$ School of Statistics, Southwestern University of Finance \& Economics, Chengdu, China \\ Correspondence: Sheng Li, School of Business Administration, Southwestern University of Finance \& Economics, \\ Chengdu, China. Tel: 86-28-61800046, E-mail: soonl@ sina.com
}

Received: August 6, 2017

Accepted: September 23, 2017

Online Published: September 24, 2017

doi:10.5430/bmr.v6n3p94

URL: https://doi.org/10.5430/bmr.v6n3p94

The authors thank for the financial support from humanity and social science planning of China Ministry of Education (12YJA630061), science \& technology supporting plan of Sichuan Province (2011FZ0015) and soft science study plan of Sichuan Province (2011ZR0170).

\begin{abstract}
We develop a game model to describe the game between a seller and a group-buying website in order to study the operating mode of Chinese static group-buying $(\mathrm{GB})$. A seller sells products by a website and allocates a proportion of revenue to it. Based on this mode we establish the profit function of the seller and that of the GB website. The website decides its allocation proportion and the sale price of its products according to the profit maximization principle and the revenue sharing proportion in the contract. We then analyze the relationship among different parameters and find that the products' price decreasing with the increasing of the revenue sharing proportion. In addition, there also exists an optimal GB period to maximize the seller's profit in a GB.
\end{abstract}

Keywords: Group-buying(GB), Pricing, Stackelberg game, Website-dominant

\section{Introductions}

Group-buying schemes have been in vogue for many years, particularly in the context of selling on television via the popular Home Shopping Network. Web based variants of group buying have recently received a lot of attention as part of the wave of innovative online market-based mechanisms such as auctions, reverse auctions, and Priceline's "name-your-own price" scheme. While there is a rich history of analytical research in auctions, spanning at least 40 years, we believe that this paper is the first analytical model of static group buying prevailing in China.

In 2008, the earliest ancestor, Groupon, was founded. It provides the network group-buying and supply a discounted product every day, which usually is a kind of regional service product and a customer can only buy it once a day. As a new consumer pattern, Groupon is an integration of electronic commerce, Web 2.0, internet advertisement and social intercourse. The propelling of Groupon ignites the tide of group-buying(GB) all over the world. Since 2010, the group-buying market in China flourishes with a different operation mode from that of Groupon.

Groupon's group-buying style has a feature that the product's price will get a quantity discount with the changing of number of consumes joining in the group-buying, so the price is unknown before a consumer who joins in this purchasing. In China, the prevailing group-buying networks usually display the fixed product price in the website, and the consumers can make the buying decision based on the corresponding information. On the basis of China group-buying style, the pricing of GB products in the website-dominant is studied in this paper.

The outline of this paper is as follows. A review of relevant literatures is presented in section 2. We introduce the model and describe the optimal solutions, then present results discussion and a give a numerical example in section3. Section 4 concludes. 


\section{Literature Review}

\subsection{The Economics Principal and Operation Mode of GB}

$\mathrm{Li}$ (2006) studied the game behavior between consumers and the merchants from the perspective of static game and dynamic one. In static game, the firm has two choices: one is to trade with consumers directly, the second is to sell the products to consumer by intermediary dealers. There are game behavior among the firm, consumers and dealers, and a Nash equilibrium (GB, GB). Zhang et al (2007) thought that the GB behavior between consumers is a kind of cooperation game, thus a unity of consumers could strengthen their bargaining power and compel the dealer sell its goods with more lower price. By using kernel and Shapley value the authors allocated the total transaction cost saved in the GB, and measured the real benefit which GB brought to the consumers. Liu (2011) analyzed the network GB from the perspective of economics, revealed the its social value and economic meanings, which is helpful for the seller to grasp the motivation and development trend of network GB's emerging.

Kauffman et al (2010) believed that the aim of GB is to search enough consumers quantity to get sufficient order of goods, which will lead to a lower sale price. When there is positive demand externality, a GB with bigger order will attract more consumers' participation. When there is a smaller order of goods, a demand negative demand externality maybe generates. They tried to solve the negative externality by introducing different motivation scheme and decision theory into the network GB auction, and analyzed whether the auction price and fairness of auction procedure could influence the consumers' participation into the GB auction or not.

\subsection{Product Pricing and Earning in a $G B$}

Many studies analyzed the pricing of the Groupon type GB prevailing in USA. In this schema the GB goods price varies with the changing of its quantity, there is a unitary quantity-based discount existing in its pricing schema, i.e., a price vector $P=\left(p_{1}, p_{2}, \cdots, p_{N}\right), p_{1} \geq p_{2} \geq \cdots \geq p_{N}$ exists, where $i \in[1, N]$ is the product sale quantity at the end of GB period. When the final sale quantity is $i$, the consumer should buy the product at the price $p_{\mathrm{i}}$. Chen et al (2002) pointed out that GB auction is a kind of dynamic pricing schema with the internet network as a carrier, and the consumers achieves quantity discount as a group. They proposed some assumptions such as consumers' product reserve price, bidder's risk neutral and information symmetry, and described the price offer procedure by using imperfect information symmetry dynamic game and analyzed the GB auction mode. Kauffman et al (2001) thought GB as a transformation of dynamic pricing schema, and emphsized the effect of GB by exploring the pricing process of both the buyer and seller. In a GB, the consumers centralized their purchase power to gain a price as low as possible. Moreover, they introducd some GB innovations based on the internet and recommended many innovation companies in GB, and summarized and evaluated the features of dynamic schema in GB mode and set forth its competition and sustainability in the market.Chen et al (2006) explored the optimal pricing curve of network GB based on the individual value model and stochastic arrival rate is given. Furthermore, they compared the revenue of GB with that of price listed sale and got two important conclusions: one is when scale economy is taken into accounted, the profitability of the further is higher than that of the latter; the other is when the sellers are risk-seeking, the same situation existed.

The studies on GB pricing above-mentioned are mostly based on the Groupon's operation mode and have a common feature that there is quantity discount of the goods price by the rising of the consumer number. Thus, the GB pricing studies are all almost based on the principle of "Buy on dips", which is different from the situation that the GB price is fixed and displayed on the GB webs and its fundamental mode is the price listed sale in fact. So, it is necessary to explore the pricing with website-dominant in static group-buying in China.

\section{Pricing Model for Service Products in Static Group-buying}

\subsection{Assumptions and Parameters}

\subsubsection{Basic Assumptions}

(1) The price of the group-buying goods is negative relative to its market demand, which means the demand of the products will lower when its price is high. At the time $t$ the market demand is $\lambda(t)=a e^{-\delta t}-b p_{g}, a$ is the basic market demand, which is no relative to price or GB time, but relative to the product publicity and quality of products sold in the physical retail store; $b$ is sensitivity coefficient of demand relative to the price, and it will bring down when the price is rising.

(2) A consumer in a group-buying only can buy a piece of product at most.

(3) There is no conspire behavior existing among the consumers. 
(4) The amount of products has no upper limit in the group-buying of service product.

(5) After a group-buying attains, the consumers are certain to use it in practice to reach the transaction between product suppliers and the websites.

3.1.2 The Definition of the Parameters

$D_{g}\left(p_{g}, T\right)$ is the market demand which the dealer attains a network GB.

$G$ is the amount floor level for a GB beginning.

$T$ is the time limit for a GB.

$p_{g}$ is unit price for a GB goods.

$c$ is unit cost of the seller's goods.

$\lambda(t)$ is the arriving ratio of customers at the time $t$.

$\pi(s)$ is the profit function of the seller.

$\pi(g)$ is the profit function of the GB website.

$c_{g}$ is the operation cost for GB website in unit time.

$\theta$ is the revenue sharing proportion for GB website, i.e., GB website's unit revenue is $\theta p_{g}$.

\subsection{The Decision of the Seller and GB Website in Static Group-buying}

In the realistic group-buying the merchant often use catchpenny strategy. In order to ask price favour from the merchants as far as possible, the GB websites usually set GB retaining conditions, which have two patterns: (1) the product purchasing amount reach a certain standard; or (2) the gross amount of product purchasing arrive at a certain value. Here we adopt the first pattern, i.e., when the number of consumers joining in the GB reach the minimum limit $G$, the GB will come into existence. Moreover, the GB service products are consuming types, such as KTV, food and beverage service, and knead and health care et al., and the consumer should make an appointment before using these service, so we can make an assumption that there is no upper limit for the GB products, i.e., the service capacity of the merchant have no limits.

The decision steps for a seller and a GB website are as follows:

Step 1. The GB website determine the charge strategy (the GB period is fixed as $T$ ) when it is direct against the product cost submitted by the seller.

Step 2. When receiving the charge strategy of the GB website, the seller decides the price and amount of products in the GB.

According to the above decision steps, we bring out the two player's decisions from step 2 using inverse method.

3.2.1 Charge Strategy of the Website and the Sale Price and Quantity Floor Level of GB Decided by the Seller

First, set a fixed GB period $T$. Facing with the revenue sharing percentage $\theta$ provided by the network, the merchant should decide the price and lower limit amount of GB. Assume that the seller provide only one kind of product for the GB, the market demand of the products are $D_{g}\left(p_{g}, T\right)=\int_{0}^{T}\left(a e^{-\delta t}-b p_{g}\right) d t$. On the condition of GB period is given in advance, we have:

$$
D_{g}\left(p_{g}, T\right)=\int_{0}^{T}\left(a e^{-\delta t}-b p_{g}\right) d t=\frac{a}{\delta}\left(1-e^{-\delta T}\right)-b p_{g} T
$$

When the GB period $T$ is finished, if $D_{g}\left(p_{g}, T\right) \geq G$, which means the GB succeeds. Therefore, the seller will sell the corresponding products and give the network operation fee according to the promised proportion, i.e., once a product is sold, the merchant will get $(1-\theta) p_{g}-c$. Thus, the profit of the merchant is: 


$$
\begin{aligned}
\pi(s) & =\left[(1-\theta) p_{g}-c\right] \cdot D_{g}(p, T) \\
& =\left[(1-\theta) p_{g}-c\right] \cdot\left[\frac{a}{\delta}\left(1-e^{-\delta T}\right)-b p_{g} T\right]
\end{aligned}
$$

Set $A=\frac{a}{\delta}\left(1-e^{-\delta T}\right)$, we get:

$$
\begin{aligned}
\pi(s) & =\left[(1-\theta) p_{g}-c\right] \cdot\left(A-b p_{g} T\right) \\
& =-(1-\theta) b T p_{g}^{2}+[A(1-\theta)+b c T] p_{g}-A c
\end{aligned}
$$

To maximize the seller's profit in GB, we get the first order derivation with respect to $p_{\mathrm{s}}$. we have:

$$
\frac{\partial \pi(s)}{\partial p_{g}}=-2(1-\theta) b T p_{g}+[A(1-\theta)+b c T]
$$

For $\frac{\partial^{2} \pi(s)}{\partial p_{g}{ }^{2}}=-2(1-\theta) b T<0$, let (4) equal to zero, we can get the extreme point:

$$
p_{g}=\frac{A(1-\theta)+b c T}{2(1-\theta) b T}
$$

For the formula (2) is workable under the condition that $D_{g}\left(p_{g}, T\right) \geq G$, i.e., $A-b p_{g} T \geq G$, we have:

i.e.

$$
\begin{gathered}
p_{g} \leq \frac{A-G}{b T} \\
\frac{A(1-\theta)+b c T}{2(1-\theta) b T} \leq \frac{A-G}{b T}
\end{gathered}
$$

Put (5) into (6), we can get:

$$
G \leq \frac{A(1-\theta)-b c T}{2(1-\theta)}
$$

This is to say that the quantity floor level of GB is no more than $\frac{A(1-\theta)-b c T}{2(1-\theta)}$, the GB will succeed.

Theorm 1. When other conditions are fixed, the unit product price in GB $p_{g}$ reduces with the revenue-sharing proportion $\theta$ is increasing.

Proof. From (5) we get:

$$
p_{g}=\frac{A}{2 b T}+\frac{c}{2(1-\theta)}
$$

Let us solve the first order derivation of (9) with respect to $\theta$, we have:

$$
\frac{\partial p_{g}}{\partial \theta}=-\frac{2}{(1-\theta)^{2}}<0
$$

Formula (10) means that with the increase of unit product price in GB, once a product is sold to consumers, the seller must lower revenue sharing proportion and pay the lower ratio revenue to the GB website. However, the market demand of the products will reduce at the same time. As mentioned above, the purpose of the merchant joining in a GB is to propagandize its products in order to enhance the product awareness and pursue a good effect on its product sale and sustainable development. In reality, the merchant is more likely to reduce the product's price and enhance the network's revenue sharing ratio in order to get more sale quantity.

\subsubsection{The GB Website's Optimal Charging Decision}

Whether a GB achieves or not, the network will pay network operational costs such as advertisement and staff salary et al. The longer GB's period is, the larger GB's corresponding cost is because the website wants to maintain operating. Assume that the unit operating cost of the GB is $c_{g}$. When the GB achieved, the seller will give a part of 
revenue to the network according to pre-said sharing proportion $\theta$. Then, the profit function of GB website is:

$$
\pi(g)=\theta p_{g} \cdot D_{g}\left(p_{g}, T\right)-c_{g} T=\theta p_{g} \cdot\left(A-b p_{g} T\right)-c_{g} T
$$

Substitute $p_{g}$ and $D_{g}\left(p_{g}, T\right)$ into (11), we have:

$$
\begin{aligned}
\pi(g) & =\theta \cdot \frac{A(1-\theta)+b c T}{2(1-\theta) b T} \cdot\left[A-b T \frac{A(1-\theta)+b c T}{2(1-\theta) b T}\right]-c_{g} T \\
& =\theta \cdot \frac{A(1-\theta)+b c T}{2(1-\theta) b T} \cdot \frac{A(1-\theta)-b c T}{2(1-\theta)}-c_{g} T \\
& =\theta \cdot \frac{A^{2}(1-\theta)^{2}-b^{2} c^{2} T^{2}}{4(1-\theta)^{2} b T}-c_{g} T=\frac{A^{2}}{4 b T} \theta-\frac{b T c^{2}}{4} \frac{\theta}{(1-\theta)^{2}}-c_{g} T
\end{aligned}
$$

To maximize the GB website's profit function, we should solve first-order and second-order derivation of $\pi(g)$ with respect to $\theta$. We have

$$
\begin{gathered}
\frac{\partial \pi(g)}{\partial \theta}=\frac{A^{2}}{4 b}-\frac{b c^{2}}{4}\left[\frac{(1-\theta)^{2}+2 \theta(1-\theta)}{(1-\theta)^{4}}\right] \\
=\frac{A^{2}}{4 b T}-\frac{b T c^{2}}{4}\left[\frac{1}{(1-\theta)^{2}}+2 \frac{\theta}{(1-\theta)^{3}}\right] \\
\frac{\partial^{2} \pi(g)}{\partial \theta_{g}^{2}}=-\frac{b T c^{2}}{4}\left[\frac{2(1-\theta)}{(1-\theta)^{4}}+2 \frac{(1-\theta)^{3}+3 \theta(1-\theta)^{2}}{(1-\theta)^{6}}\right] \\
=-\frac{b T c^{2}}{2(1-\theta)^{4}}\left[(1-\theta)+\frac{(1-\theta)^{3}+3 \theta(1-\theta)^{2}}{(1-\theta)^{2}}\right] \\
=-\frac{b T c^{2}}{2(1-\theta)^{4}}[(1-\theta)+(1-\theta)+3 \theta]=-\frac{b T c^{2}(2+\theta)}{2(1-\theta)^{4}}<0
\end{gathered}
$$

Set (13) equal to zero, we have equation (15) below.

$$
\frac{A^{2}}{4 b T}-\frac{b T c^{2}}{4}\left[\frac{1}{(1-\theta)^{2}}+2 \frac{\theta}{(1-\theta)^{3}}\right]=0
$$

Set $x=1-\theta(0<x<1)$, the equation (15) can be transformed into (16).

$$
x^{3}+\frac{b^{2} c^{2} T^{2}}{A^{2}} x-\frac{2 b^{2} c^{2} T^{2}}{A^{2}}=0
$$

Solve the equation (16), we get the discriminant criterion from the Cardano formula:

$$
\Delta=\left(-\frac{b^{2} c^{2} T^{2}}{A^{2}}\right)^{2}+\left(\frac{b^{2} c^{2} T^{2}}{3 A^{2}}\right)^{3}=\left(\frac{b c T}{A}\right)^{4}+\frac{1}{27}\left(\frac{b c T}{A}\right)^{6}>0
$$

Thus, the equation has solutions which are a real root and two imaginary roots. The real one is:

$$
x=\sqrt[3]{\frac{b^{2} c^{2} T^{2}}{A^{2}}+\sqrt{\left(\frac{b c T}{A}\right)^{4}+\frac{1}{27}\left(\frac{b c T}{A}\right)^{6}}}+\sqrt[3]{\frac{b^{2} c^{2} T^{2}}{A^{2}}-\sqrt{\left(\frac{b c T}{A}\right)^{4}+\frac{1}{27}\left(\frac{b c T}{A}\right)^{6}}}
$$

So,

$$
\theta=1-\sqrt[3]{\left(\frac{b c T}{A}\right)^{2}+\sqrt{\left(\frac{b c T}{A}\right)^{4}+\frac{1}{27}\left(\frac{b c T}{A}\right)^{6}}}-\sqrt[3]{\left(\frac{b c T}{A}\right)^{2}-\sqrt{\left(\frac{b c T}{A}\right)^{4}+\frac{1}{27}\left(\frac{b c T}{A}\right)^{6}}}
$$


For $x, \theta$ in above process are got under the condition that the GB is achieved, the formula (20) still be satisfied in below.

Where

$$
\begin{gathered}
G \leq \frac{A(1-\theta)-b c T}{2(1-\theta)} \\
A=a+\frac{\lambda_{0}}{\delta}\left(1-e^{-\delta T}\right)
\end{gathered}
$$

To explain the meanings of these variables vividly, a numerical example will be provided in the following section.

Theorm 2. Under the condition that other parameters are given, there is an optimal GB period $T$ which leads to achieve the maximum of the merchant's profit function $\pi(s)$ in a GB.

Proof. Solve the first order partial derivation of the merchant's profit function $\pi(s)$ with the respect to the GB period $T$, we have:

And

$$
\begin{gathered}
\frac{\partial \pi(s)}{\partial T}=-(1-\theta) b p_{g}^{2}+p_{g}(1-\theta) \frac{\partial A}{\partial T}+b c p_{g}-c \frac{\partial A}{\partial T} \\
A=\frac{a}{\delta}\left(1-e^{-\delta T}\right)
\end{gathered}
$$

Thus, we have

$$
\frac{\partial A}{\partial T}=a e^{-\delta T}
$$

Substitute (23) into (21), we have

$$
\begin{gathered}
\frac{\partial \pi(s)}{\partial T}=-(1-\theta) b p_{g}^{2}+a p_{g}(1-\theta) e^{-\delta T}+b c p_{g}-a c e^{-\delta T} \\
\frac{\partial^{2} \pi(s)}{\partial T^{2}}=-a \delta p_{g}(1-\theta) e^{-\delta T}+a \delta c e^{-\delta T}=a \delta e^{-\delta T}\left[c-p_{g}(1-\theta)\right]
\end{gathered}
$$

The seller must set the GB price which satisfies with $p_{g}(1-\theta)>c$ so that it can gain a certain profit in a GB. Thus, we have $\frac{\partial^{2} \pi(s)}{\partial T^{2}}<0$. We can conclude that there is an optimal GB period $T$ which leads to achieve the maximum of the merchant's profit function in a GB.

\subsection{Numerical Example}

Set $a=10, b=1, \delta=0.1, c=2, c_{g}=2, T=10$, use Matlab to solve the revenue sharing ratio $\theta=0.4718$ and unit product GB price $p_{g}=5.0539$. Put the values of $\theta, p_{g}$ into the profit function of GB website $\pi(g)$ and that of the merchant $\pi(s)$ respectively, we have:

$\pi(s)=8.4822, \pi(g)=10.2194$

From $G \leq \frac{A(1-\theta)-b c T}{2(1-\theta)}$ we get $G_{\max }=12.6727$, which means the quantity limit of GB is no more than 12 units, this GB will achieve before the GB period finishes.

When the above parameters are fixed, we can get the profit curve of the merchant as shown in Figure 1 in a certain period $T$, where we assume that $T \in[1,20]$. We can conclude that the profit of the merchant has showed first increasing and then decreasing. 


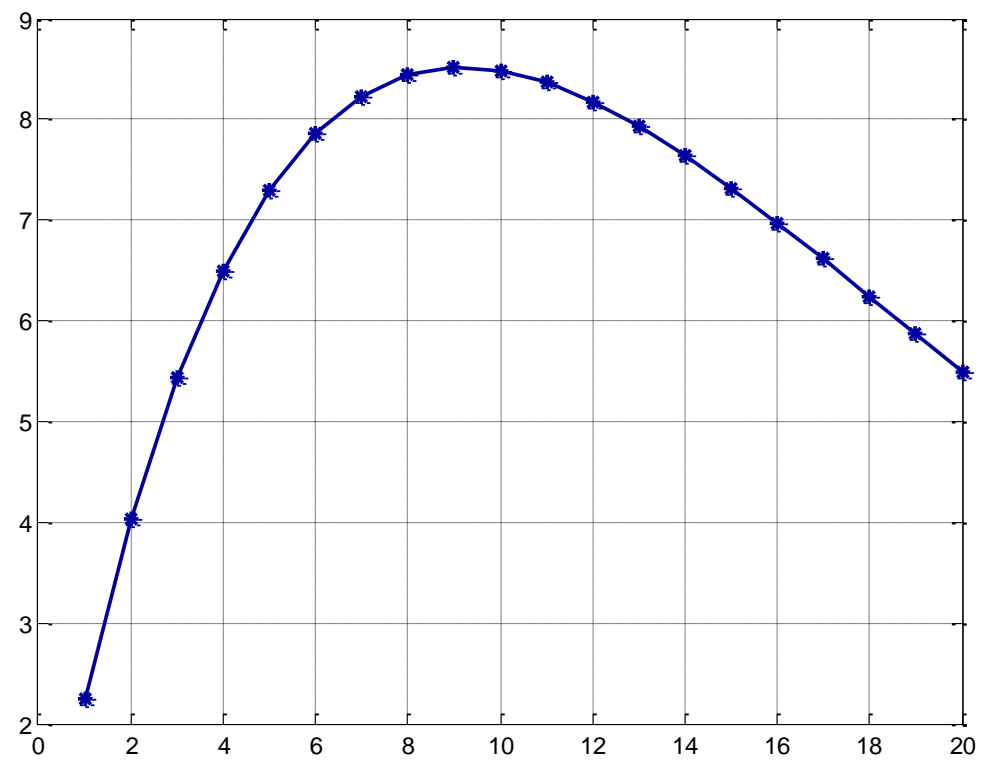

Figure 1. The relationship between the seller's profit and GB period (when other parameters are given)

\section{Conclusions}

In this paper, a Stackelberg game process for GB between a merchant and a network is studied. As a sponsor in a new emerging consume mode, GB, the network act as a dominator. In the GB procession, the network provides the seller with an exhibition and sale platform for its products. On one hand, GB can promote the merchant's products timely; and on the other hand, the seller could propagandize its own products using the word of mouth of the network. In return, the seller should assign a part of revenue to the GB website in order to get "win-win".

Here we established the profit function of the seller and that of the website respectively in GB process, and derived the revenue sharing ratio of the network and GB product's sale price of the seller. Under the assumption that the GB can retain in a certain period $T$, we get the maximum limit of quantity of the GB product. Moreover, we got some thermos and deductions after the relationship between the revenue sharing ratio of the network and GB product's sale price of the seller, and that between GB period and the seller's profit were analyzed.

We only studied decision process that a seller participating a GB and only sell products on the website here. In reality, most of sellers sell their products both in offline channel (such as department store, franchise house et al.) and in GB one. Therefore, the seller's decision process contains online and offline channel simultaneously should be studied in the future. Moreover, for we only analyze the channel composed by one seller and one GB website here, the further research should introduce a game process which contains multiple sellers and multiple websites or put supply chain coordination into GB game so that we can acquire more valuable results and enhance research conclusion's practicality. Another possible extension of this study is to group-buying mechanisms under uncertainty about product quality. When buyers can get signal about product quality from the bids of auctions, group-buying mechanisms can be a powerful way for the seller to induce buyers to signal product quality information to each other. Future research could extend our model to study the impact of these different factors such as uncertainty, risk aversion, bounded rationality, moral risk, et al.

\section{References}

Anand K. S. \& Aron R. (2003). Group Buying on the Web: A Comparison of Price-Discovery Mechanisms. Management Science, (11), 1546-1562, Special Issue. https://doi.org/10.1287/mnsc.49.11.1546.20582

Anderson, C. K., Wilson, J. G. (2003). Wait or buy? The strategic consumer: Pricing and profit implications. Journal of the Operational Research Society, (3), 299-306. https://doi.org/10.1057/palgrave.jors.2601497

Chen J., Chen X.L., Song X.P. (2002). Bidder's strategy under group-buying auction on the internet. IEEE Transactions on Systems, Man and Cybernetics. Part A: Systems and Humans, 32(6), 680-690. https://doi.org/10.1109/TSMCA.2002.807029 
Chen J., Chen X.L., Song X.P. (2007). Comparison of the group-buying auction and the fixed pricing mechanism. Decision Support Systems, (43), 445-459. https://doi.org/10.1016/j.dss.2006.11.002

Chen, R. R., Roma,P. (2011). Group Buying of Competing Retailers, Production and Operations Management, (2), 181-197. https://doi.org/10.1111/j.1937-5956.2010.01173.x

Guan Z., Ren, J. (2011). Optimal pricing policy research for perishable hi-tech products with uncertain demand. Journal of System Engineering, 26(1), 113-120(in Chinese).

Hsieh, F. S., \& Lin, J. B. (2012). Assessing the benefits of group-buying-based combinatorial reverseauctions. Electronic Commerce Research and Applications, (4), 407-419. https://doi.org/10.1016/j.elerap.2012.02.003

Jing X. and Xie J. (2011). Group Buying: A New Mechanism for Selling Through Social Interactions. Management Science, ( 8), 1354-1372. https://doi.org/10.1287/mnsc.1110.1366

Kauffman R. J., Wang B. (2002). Bid togegher, buy together: on the efficacy of group-buying business models in internet-based selling. In Lowry P. B., Cherrington J. O., and Watson R. R. (eds.), Handbook of Electronic Commerce in Business and Society, CRC Press, Baca Raton, FL.

Kauffman R. J., Lai H., Ho C. T. (2010). Incentive mechanisms, fairness and participation in online group-buying auctions. Electronic Commerce Research and Applications, (9), 249-262. https://doi.org/10.1016/j.elerap.2008.11.009

Kim, J. B. (2015). A fixed pricing group buying decision model: Insights from the social perspective. International Journal of E-Business Research, (2), 40-59. https://doi.org/10.4018/ijebr.2015040103

Li, C. (2006). The game analysis of group-buying mode. Journal of Guangdong College of Finance \& Economics, $5(2), 61-63$.

Liang, X., Ma, L., Xie, L., et al. (2014). The informational aspect of the group-buying mechanism. European Journal of Operational Research, (1), 331-340. https://doi.org/10.1016/j.ejor.2013.10.031

Lim, W. M. (2014). Sense of virtual community and perceived critical mass in online group buying. Journal of Strategic Marketing, (3), 268-283. https://doi.org/10.1080/0965254X.2013.876068

Liu, T. (2011). The economics analysis of network group-buying, E-commerce, (1), $43-45$ (in Chinese)

Liu, Y., \& Sutanto, J. (2012). Buyers' purchasing time and herd behavior on deal-of-the-day groupbuying websites. Electronic Markets, (2), 83-93. https://doi.org/10.1007/s12525-012-0085-3

Ni G., Luo L., Xu, Y., et al. (2015). Optimal decisions on group buying option with a posted retailprice and heterogeneous demand. Electronic Commerce Research and Applications, (1), 23-33. https://doi.org/10.1016/j.elerap.2014.10.005

Pan, W., Wang, S., Hua, G., Zhang, J. (2010). Analysis of dynamic pricing and order policies for "click-and-mortar" firms. Theory and Practice of System Engineering, 30(2), 236-242 (in Chinese).

Yu, D. (2010). Groupon: Group-buying convergence. Business Review, (9), 132-135.

Yuan, P., Liu, Y., Liu, W., Li, X., Nie, G. (2015). How to measure the operating efficiency of internet group-buying platform? Procedia Computer Science, (55), 213-220. https://doi.org/10.1016/j.procs.2015.07.036

Zhang X. (2007). The analysis on group-buying behavior based on cooperation game, Jiangxi Science, 25(3), 267-269.

Zhou, G., Xu, K., Liao, S. (2013). Do starting and ending effects in fixed-price groupbuying differ? Electronic Commerce Research and Applications, (2), 78-89. https://doi.org/10.1016/j.elerap.2012.11.006 